\title{
Students' Weakness Detective in Traditional Class
}

\section{Artificial Intelligence}

\author{
Fatimah Altuhaifa \\ College of Computer Engineer \& Science \\ Prince Mohammed bin Fahd University \\ Alkhobar, Saudi Arabia
}

\begin{abstract}
In Artificial Intelligent in Education in learning contexts and domains, the traditional classroom is tough to find students' weakness during lecture due to the student's number and because the instruction is busy with explaining the lesson. According to that, choosing teaching style that can improve student talent or skills to performs better in their classes or professional life would not be an easy task. This system is going to detect the average of students' weakness and find either a solution for this or instruct a style that can increase students' ability and skills by filtering the collected data and understanding the problem. After that, it provides a teaching style.
\end{abstract}

Keywords-emotional learner prediction; voice identifier and verifier; weakness detecting; artificial intelligent in education

\section{INTRODUCTION}

Students' weakness is one of the most important factors that prevent students' improvement. For that, researchers built a lot of e-learning that detects student's difficulty and provides the students with suitable learning style. Not all students have the motivation to use e-learning while most of them care to attend their classes. This paper aims to find a solution for students' weakness in an environment such as a traditional classroom. Understanding students' character is the primary factor for detecting difficulty. Analyzing students' emotion and activities can obtain the nature of that student.

\section{SELECT A PROBLEM}

This paper purposed to invent a solution for a system that helps in improving and enhancing student's skills and weakness. It will find the average of students' weakness in the class by collecting learners' emotion, reasoning the data and representing solution depending on the database or knowledge-based that the system has. The aim of this software will be reached by collecting information about each student at class and touching student's voice and analyzing it to find the suitable teaching style.

\section{THE SOLUTION}

As each student has his/her weakness that can affect his/her performance in the professional life, this system detects the average of students' vulnerability for every class. Then it provides a teaching style that helps in improving students' strengths.

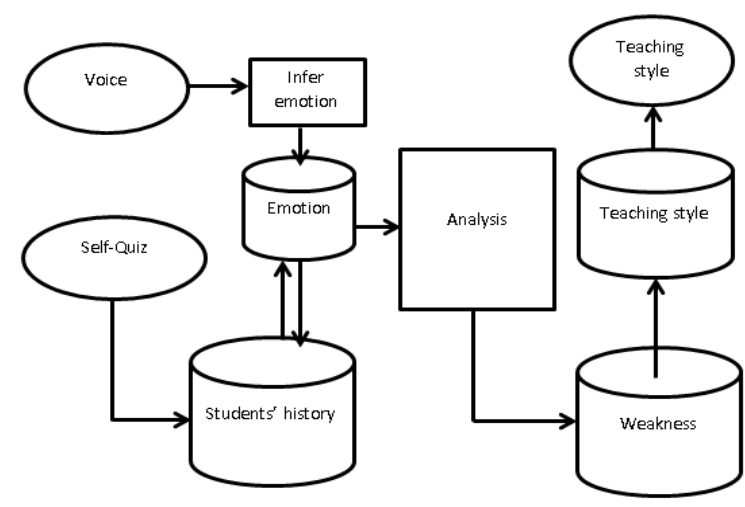

Fig. 1. Clarifying the solution

The system has one output and two inputs; one is students' voice, and the other is self-quiz for each student.

The system will touch the Students' voice for one week. Then the tone of speech is sent to software which will infer student's emotion. The system will have a database for storing students' emotion. Each student will have an ID, which is used to save assumed feelings with the unique voice. The ID with the unique voice will prevent the system from keeping the same emotion for the same student. Also, the system will add new colon if it is needed. Then the average for emotion will be taken and saved.

TABLE I. The SAVED EMOTIONS OF STUDENTS

\begin{tabular}{|l|l|l|l|l|}
\hline ID & Hash1 & Hash2 & Hash3 & Hash4 \\
\hline $\mathbf{0 1}$ & Shy & $\begin{array}{l}\text { Lack of self- } \\
\text { confidence }\end{array}$ & & \\
\hline $\mathbf{0 2}$ & Sad & Fear & Anxiety & Despair \\
\hline $\mathbf{0 3}$ & Angry & Anxiety & & \\
\hline $\mathbf{0 4}$ & $\begin{array}{l}\text { Lack of self- } \\
\text { confidence }\end{array}$ & & & \\
\hline $\mathbf{0 5}$ & shy & & & \\
\hline
\end{tabular}

TABLE II. SHOWS THE AVERAGE OF EMOTIONS

\begin{tabular}{|l|l|l|l|}
\hline Average & Shy & Anxiety & $\begin{array}{l}\text { Lack of self- } \\
\text { confidence }\end{array}$ \\
\hline
\end{tabular}


The system has several emotions such as self-esteem, shy, fear, cooperative, sadness and exciting. And these feelings can be changed as the user want.

The second input is a self-quiz which each student is going to take at every beginning of the semester. This self-quiz will focus on student's character to enable the system inferring the weakness. Every student has to use his/her ID for accessing to this self-quiz, and this will prevent the student from doing the quiz more than once. After taking the information, the information will be sent to the database that has the history for each student. The most characters that system will focus on are self-confidence, self-awareness, work in the team and the ability for improving.

After the system stores the information in the students' history and stores the inferred emotions in the emotion database, the system will send the information and the inferred emotions sent to investigate block. The analyzing block will examine the self-quiz for each student, and it will put the result in the table, then it will take the average of students' characters. And because the result of self-quiz can be $50 \%$ for one character and $50 \%$ for another character, the system can record more than one or two characters for one ID.

TABLE III. DETECTING More THAN ONE CHARACTERISTIC FOR THE SAME PERSON

\begin{tabular}{|l|l|l|l|l|}
\hline ID & Character1 & Character2 & Character3 \\
\hline $\mathbf{0 1}$ & $\begin{array}{l}\text { Lack of } \\
\text { Self-awareness }\end{array}$ & $\begin{array}{l}\text { Lack of work } \\
\text { in team }\end{array}$ & \multicolumn{2}{|l|}{} \\
\hline $\mathbf{0 2}$ & self-confidence & & & \\
\hline $\mathbf{0 3}$ & self-confidence & & & \\
\hline $\mathbf{0 4}$ & \multicolumn{2}{|l|}{ Lack of improving } & & \\
\hline
\end{tabular}

TABLE IV. THE AVERAgE From THE FIRST TABLE

\begin{tabular}{|l|l|}
\hline Average & self-confidence \\
\hline
\end{tabular}

Then the analysis block will relate the character and the emotion to each other to grip an appropriate weakness to the class. The system will send the gripped vulnerability to weakness the database which has a table for vulnerability and a proper teaching style for each weak point. After the system chooses the style of education, the system will send the result to the screen as a report which has the method of teaching.

Also, there is another problem that system can face. This problematic is one pair voice come from outside the class to the software. For solving this problem, the system will have an application that can be work on and work off by the instructor. This application is identifying students' voice at the beginning of the semester, or when any new student attends the class, who has done late registration for the course, the application can identify the students' voice when each student identify himself/herself to everyone at the first class of the semester.

1) How can the voice be touched?

2) How will the emotion extract from the tone of speech?
3) How can the system identify and verify the vocal sound?

4) What is the important of identifying and confirming the voice?

5) How are the data going to be analyzed?

6) Which is the type of teaching style going the system has?

7) How can the system collect the students' data?

8) How can the system deal with overlapping voice?

\section{METHODOLOGY AND ANSWERING SOME OF THE QUESTIONS}

Most of the work will depend on how to handle the voice so the answer will be depending on understanding the natural of the sound and its signal. And more on the signal, because each type of speech has different vibration, frequency and signal which can help in understanding students' natural.

\section{A. Catching the Voice}

As known the voice travels through the medium (air, water, etc.) as a vibration. The system will have a Neumann microphone that one of the employees in the school has to install it on the ceiling. The mounted instrument will allow each sound to be easy to catch. This kind of tool is upright for using in studio, TV and room because it can detect the voice from a long distance.

\section{B. Extracting Voice's Feature}

When the microphone receives the speech, it will send it to the system. The system will extract at least one feature of the voice signal then it will determine the emotion that is related to the voice signal [1]. Each sound has different vibration, for example, the noise has high waves, and these waves are close while the beneath sound has vibrations that have small distant from each other.

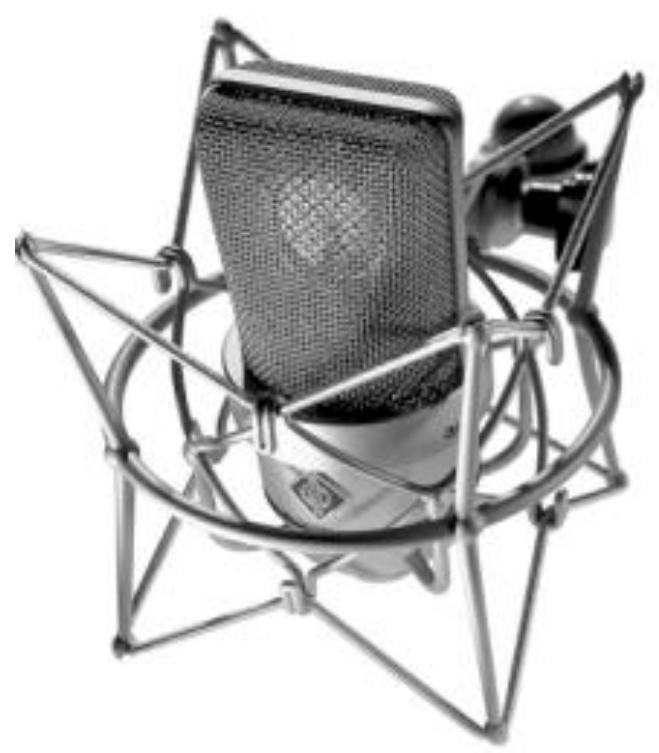

Fig. 2. Neumann microphone [2] 


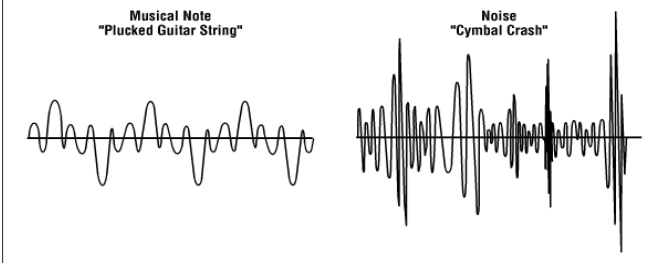

Fig. 3. Diversity in voice's frequency [1]

The Sound has three composed loudness, pitch, and timbre. Loudness is a strength or weakness of sound due to air pressure. The application can know the pitch by the frequency of the voice and rate repetition. Timber is the tone, color, or texture [1].

\section{The Ability of Extraction Emotion From The Voice}

A.Valery works in a system that can detect emotion in the voice signal. They claim that each emotion has different frequency and vibration. The system uses Object Oriented Programming (OOP). This programming helps in developing computer software and doing an analysis. This system receives the voice and does an analysis to it [3].

\section{Identifying Verifying Voice}

One of the inputs to the system is students' speech which will be touched in the class by the microphone for one week every month. Then, the vibrations of voice will be analyzed to infer the emotion of student. The system will need to check student's awareness every month to check students' improvement. Also, avoiding duplicate in emotion for the same student will be required for getting a perfect result. The system will need to recognize the voice and assigns it to specific ID, and it will need to verify the voice to ensure that voice has an ID to prevent the system from saving the duplicate voice of the same student. For this purpose, the system will have a database for storing voice's feature in it. The Hidden Markov Models with the Gaussian Mixtures (HMM-GM) is the used method [3]. With this approach, there are three ways for extraction voice's feature. These are filters, Speaker Dependent Frequency Filter Bank (SDFFB) and Speaker Dependent Frequency Cepstrum Coefficients (SDFCC). The filters work to find the domain of frequency by defining the discrete frequency domain. According to the different in vocal sound, the SDFFB's method is Linear Prediction Coefficients, while the system cannot use the SDFCC in some types of voice recognition because it "emphasizes the speaker influence too much" [4].

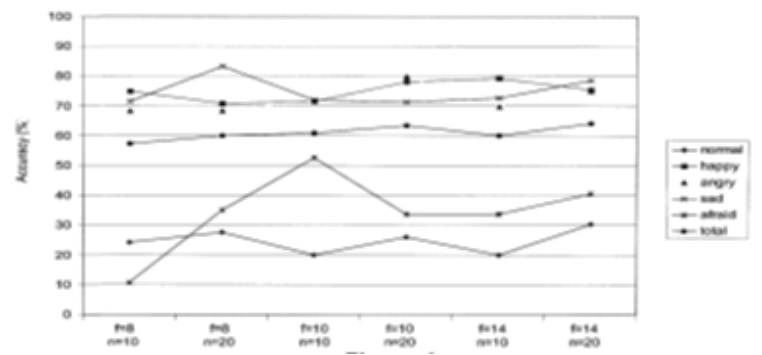

Fig. 4. It shows the different in sound frequency for diverse emotion [1]

\section{E. Ability of Distinguishing Voices in Overlapping}

T.WEI-OH and L.SHI-JIE wrote about a system that can distinguish between overlapping sounds and non-overlapping. And this system can determine who speak each part of overlapping sounds. The system will take the signal and checks if it is overlapping or not overlap then it will start analyzing the voice to determine who is speaking?[5].

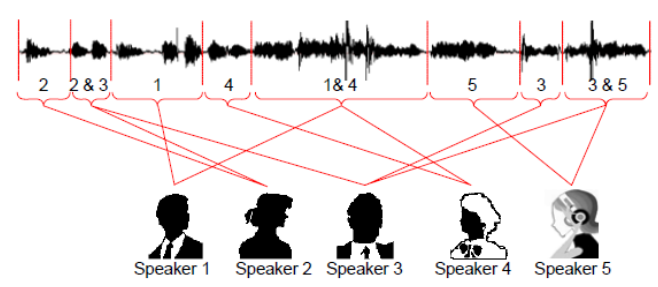

Fig. 5. Extracting the simulating voices [5]

\section{F. Avoiding Duplicating Emotion For the Same Student}

The system will need some algorithm or coding for achieving this goal. After verifying the voice and being sure if it is existing or not, then it will check the identification of the voice. It is not important to know exactly for which student this voice but it is important to assign each tone with unique ID. After recognition the voice, the system has to record the extracting emotion with its accent which means with its ID. But before recording the emotion, the system must ensure that this ID does not have this feeling. It the ID has the emotion the system will not record it while if the sense does not exist for that ID, the system has to record it.

If (newVoice $==$ OldVoice $)\{$

If $($ newEmotion $==$ OldEmtoin $)$

Add emotion;

Else

Exit $0 ;\}$

Else \{

If ( saving $==$ True $)$

Add newVoic;

Else

Exit $0 ;\}$

\section{RELATED WORKS}

This paper aimed to detect the student's knowledge state to help the system to find an appropriate learning plan for the student that improving the student and the learning effectively. It is a web-based educational system which provides the student with a quiz and observes his/her interaction on the web and his/her moving to the mouse and choosing the answer with observing the time for his/her action. Choosing appropriate learning plan depends on student diagnose. For achieving this purpose, the system will have student profile, student model, content model and learning plan. The application uses fuzzy logic supported modeling in analyzing student. The using of fuzzy logic supported modeling is depending on the student profile and the quiz [6]. The way that the system is using for analyzing student and finding the appropriate plan for him/her is the most part that is related to 
evaluating students' weakness in the class. The reason that makes it the most important part is to diagnose student individually will be needed to discover the average of weakness in the class.

N.Aghaee and S.Ören discussed in their paper the process of finding the best solution for education style for the elearning depending on the student's emotions. The primary inputs, at the System, are the student's personality and emotion while the output will be the teaching's style. The aim of this application is to inspire the student and enhance their ability. For reaching their goal, they used personality filter for software agent, emotion filter for software agent and MBTI indicator. The system has eight types of emotions which are fear, anger, sorrow, joy, disgust, acceptance, anticipation and surprise. The MBTI is the responsible for inference the suitable learning style, according to student's cognitive, emotion and character [7]. This paper related to our paper in the way in finding the appropriate learning style depending on the emotions and character but has different in the environment and how to collect the student's data. In this paper, the emotions will be inferred by facial expression while in our paper, the emotions will be inferred by using an agent that can cause analysis emotions from voice. In our paper, student's character will be assumed by student's history. In their paper, the environment is eLearning while our environment is a traditional classroom.

Another relative document to this article is A Model of the Student Behaviors in a Virtual Educational Environment, which is written by Moisil. This paper has a system that finds a suitable learning style on online for student depending on student's behavior, beliefs, and motivation. The system has different modeling in learning style for various kinds of students which help to determine the type of student performance. The system has four learning style. For achieving the most appropriate style, the designer provides the system with two types of questionnaire. One has 80 items, and the other has 40 items. The four learning style are Activists (Do), Reflectors (Review), Theorists (Conclude) and Pragmatist (Plan) [8]. This system has three agents that help in improving student's skills. These agents are a personal assistant, tutor, and the mediating agent. This system similar to our system in trying to find learning style depending on student behavior and beliefs while it differs in the environment. This system is e-learning while our system is in the real environment such as the classroom.

\section{CONCLUSION}

The purpose of this application is to increase the students' skills and ability. For accomplishing that, the weakness of the student needs to be known which will enable the system to choose an appropriate style of education. This system depends on the analyzed students' emotion and history for getting the result.

This system will need to improve analyzing part in the feature. To see how the system can do the analysis and what is the proper technique for this purpose. Also, it needs work deeply in algorithm part or coding part for being sure that the analyzing done will. In addition to that, the system needs to mention the teaching style and how this refers to each weakness.

\section{SELF-QUIZ}

1. My need to take this course now:

- High. I need it straight away for a degree, job, or other important reason.

- Moderate. I can take it on campus later or substitute another course.

- Low. It's a personal interest that I can postpone it.

2. Considering my professional and personal schedule, the amount of time I have to work on a course is:

- More than adequate for a campus class.

- The alike as for a class on campus.

- Less than adequate for a class on campus.

3. I can classify myself as someone who:

- Often I can do things before the dead time.

- Needs reminding to get things done on time.

- Puts things off until the last minute.

4. Feeling that I am one of a class is:

- Not particularly necessary for me.

- Somewhat important to me.

- Critical to me.

5. As a reader, I would classify myself as:

- Good. I usually understand the text without help.

- Average. I sometimes need help to understand the text.

- Slower than average. [5 ]

6. You have an assignment that you have to do it in group; you prefer to work with

- Friends.

- No matter with whom.

- Not with friends.

7. You are going to present your work you prefer to perform in front of

- Only Friends.

- No matter in front who.

- Only the class and your instructor without other teachers.

Do you believe in yourself? $\quad$ Yes no

Are you happy in your major? $\quad$ Yes no

Is your major mostly what you talk about? Yes no

Do you feel guilty for doing the things that you want to do?Yes no [9]

\section{REFERENCES}

[1] J. Beggs and D. Thede. Designing Web Audi. Chapter 2,The Science of Sound and Digital Audio. O'Reilly \& Associates .2001.

[2] Boré, G., \& Peus, S. (1999). Microphones Methods of Operation and Type Examples. Berlin: Druck-Centrum Fürst GmbH.

[3] A.Valery.(1999). System Method and Article of Manufacture for Detecting Emotion in Voice Signals through Analysis of a Plurality of Voice Signal Parameters. United States Patent Publication. G10L17/00; G10L17/00; (IPC1-7): G10L15/00.

[4] F.Orság. (2010). Speaker Dependent Coefficients for Speaker Recognition. International Journal of Security \& Its Applications, 4(1), 31-47. 
[5] T. WEI-HO, and L. SHIH-JIE. (2010). Speaker Identification in Overlapping Speech. Journal of Information Science \& Engineering, 26(5), 1891-1903.

[6] D. Xu, H. Wang and.K. Su (2002). Intelligent Student Profiling with Fuzzy Models. HICSS '02 Proceedings of the 35th Annual Hawaii International Conference on System Sciences (HICSS'02,3(3), 0-76951435-9.

[7] N.Aghaee and S.Ören (2008). Agents with Personality and Emotional
Filters for an E-learning Environment. 2008 Spring Simulation Multiconference (SpringSim'08)- Poster Sessions (SCS-Poster sessions 2008).Ottawa, Canada, April 14 - 17, 2008

[8] Moisil, (2008). A Model of the Student Behaviour in a Virtual Educational Environment. International Journal of Computers, Communications \& Control, 3(3), 108-115.

[9] http://www.clt.odu.edu/oso/index.php?src=pe_isdlforme_quiz 